Standards of Medical Care in Diabetes, Diabetes Care, 35(1): S11-S63.

2. International Diabetes Federation (2017). IDF DIABETES ATLAS Eighth edition 2017.

3. Bênh viện Nội tiết Trung ương (2014). Báo cáo kết quả điều tra dịch tể học bệnh đái tháo đường toàn quốc năm 2012, Hà Nội.

4. Bộ Y tế (2015). Báo cáo chung Tổng quan ngành y tế năm 2015: Tăng cường y tế cơ sở hướng tới bao phủ chăm sóc sức khỏe toàn dân, 20-21.

5. Bộ Y tế (2017). Hướng dấn chẩn đoán và điều trị đái tháo đường týp 2. Quyết đinh số 3319/QĐ-BYT ngày 19/7/2017 của Bộ trưởng Bộ Y tế V/v Ban hành tài liệu chuyên môn.

6. Lê Thị Hương Giang, Hà Văn Như (2013). Thực trạng và một số yếu tố liên quan đến tuân thư điều trị bệnh đái tháo đường týp 2 của người bệnh đang điều trị ngoại trú tại bệnh viện 198 năm 20̉13, Tạp chí Y hoc thực hành, 893(11): 93-97.

7. Đố Văn Doanh (2016). Thực trang tuân thủ điều trị của người bệnh đái tháo đường týp 2 ngoại trú tai bênh viên tỉnh Quảng Ninh năm 2016, Tap chí Khoa học Điều dưỡng, 2(2): 14-21.

8. WHO (1999). Definition, Diagnosis and classification of deabetes millitus and complication, Report of a WHO Consultation, 52.

9. Trung tâm dinh dưỡng lâm sàng Bênh viên bạch Mai (2019). Hướng dẫn chế độ ăn cho người bệnh đái tháo đường. http://www.bachmai.gov.vn/en/tin-tuc-va-sukien/bai-viet-chuyen-mon-menuleft-33/5699-trungtam-dinh-duong-lam-sang-bv-bach-mai-huongdan-che-do-an-cho-nguoi-benh-dai-thaoduong.html.

\title{
KHẢO SÁT SỰ THAY ĐỔI CHİ SỐ XƠ HOÁ GAN APRI SAU ĐẠT ĐÁP ỨNG VI RÚT BỀN VỮNG Ở BÊNNH NHÂN VIÊM GAN VI RÚT C MAN ĐƯợC ĐIỀU TRI BẰNG THUỐC KHÁNG VI RÚT TRỰC TIẾP
}

\section{TÓM TẮT}

Muc tiêu: Khảo sát hiêu quả cải thiên mức đô xơ hoá gan dựa vào chỉ số AŚT/số lượng tiểu cầu (APRI) sau khi đạt đáp ứng vi rút bền vững ở bệnh nhân viêm gan vi rút $\mathrm{C}$ mạn (HCV) được điều trị bằng kháng vi rút trưc tiếp (DAA). Đối tương và phương pháp: Mô tả cắt ngang hồi cứu trên hồ sơ bệnh án của bệnh nhân $(B N)$ viêm gan vi rút $C$ mạn, đển khám và điều trị ngoại trú tại Phòng khám viêm gan - Bênh viện Đại học Y Dược TP. HCM, từ tháng 01/2018 đến 12/2019. BN được chỉ định điêu trị bằng các phác đồ DAA trong 3 tháng, thu thập các số liệu lâm sàng và cân lâm sàng tại thời điểm trước điều trị, sau khi kết thúc điều trị 3 tháng, 6 tháng và 12 tháng. Đánh giá mức độ xơ hoá gan dựa trên APRI. Kết quả: Trong 184 BN đủ tiêu chuẩn, có $113(61,4 \%)$ là nữ. Tuổi trung bình là $57,1 \pm 13,4$, Có 96/184 (52,2\%) BN chưa có xơ gan. Trên nhóm BN chưa có xơ gan, APRI thay đổi có ý nghĩa thống kê tại thời điểm 6 tháng sau khi kết thúc điêuu trị so với ban đâu $(0,71 ; 0,32 ; \mathrm{p}=0,012)$. Không có sự khác biệt có ý nghĩa thống kê khi so sánh ở thời điểm 12 tháng $(0,32)$ và 6 tháng $(0,31)$ sau khi kết thúc điều trị $(\mathrm{p}=0,385)$. Trên nhóm BN xơ gan, APRI giảm có ý nghĩa thống kê ở tất cả các khoảng giá trị ở thời điểm 6 tháng sau khi kết thúc điều tri so với giá trị ban đầu $(1,13 ; 0,41 ; p<0,001)$. Kết luận: APRI thay đổi có ý nghĩa thống kê ở thời điểm 6 tháng sau

${ }^{1}$ Đại học Y Dược Thành phố Hồ Chí Minh Bệnh viện Chợ Rẫy, Thành phố Hồ Chí Minh Chịu trách nhiệm chính: Võ Duy Thông

Email: duythong@ump.edu.vn

Ngày nhận bài: 23.3.2021

Ngày phản biên khoa học: 18.5.2021

Ngày duyệt bài: 25.5.2021

\section{Võ Duy Thông',2, Bùi Thị Thu Vân ${ }^{1}$}

khi kết thúc điều trị bằng $\mathrm{DAA}$. Do đó, $\mathrm{BN}$ HCV nên được điều trị DAA sớm để hạn chế diễn tiến của bệnh gan man tính.

Tứ khóa: Xơ gan, APRI, viêm gan C mạn

\section{SUMMARY}

CHANGE OF APRI AFTER SUSTAINED VIROLOGICAL RESPONSE IN CHRONIC HEPATITIS C PATIENTS TREATED WITH DIRECT-ACTING ANTIVIRAL AGENTS

Objective: To investigate the effectiveness of direct-acting antiviral agents (DAA) in improving liver fibrosis based on AST to Platelet Ratio Index (APRI) after achieving sustained virological response in patients with chronic hepatitis C virus (HCV). Patients and methods: We conducted a retrospective cross-sectional study on medical records of outpatients with chronic hepatitis $\mathrm{C}$ virus at Hepatitis clinic, University Medical Center of Ho Chi Minh City from January 2018 to December 2019. Patients were treated with 3-month DAA regimens. Clinical and laboratory data were collected before treatment, at 3 months, 6 months and 12 months after the end of treatment. The degree of liver fibrosis was assessed based on APRI. Results: Among 184 eligible patients, $113(61.4 \%)$ were female. The mean age of patients was $57.1 \pm 13.4$. There were 96/184 $(52.2 \%)$ without cirrhosis. In patients without cirrhosis, APRI was changed significantly at 6 months after the end of treatment compared to baseline $(0.71 ; 0.32 ;$ respectively, $\mathrm{p}=0.012)$. There was no statistically significant difference between the 12month APRI and 6-month APRI after the end of treatment $(0.32 ; 0.31$; respectively, $p=0.385)$. In cirrhotic patients, APRI decreased statistically significantly at all ranges at 6 months after the end of treatment compared to those at baseline $(1.13 ; 0.41$; 
respectively, $\mathrm{p}<0.001)$. Conclusion: APRI was changed significantly in patients with HCV at 6 months after the end of DAA treatment. Therefore, patients with HCV should receive early DAA therapy to limit progression of chronic liver disease.

Keywords: Cirrhosis, APRI, chronic hepatitis C virus (HCV)

\section{I. ĐĂT VẤN ĐỀ}

HCV có thể gây viêm gan cấp, viêm gan mạn, tiến triển thành xơ gan, ung thư tế bào gan [1]. Theo Tổ chức $\mathrm{Y}$ tế thế giới (WHO), viêm gan $\mathrm{C}$ được tìm thấy trên toàn thế giới, với tỷ lệ hiện mắc ước tính trong năm 2015 lần lượt là 2,3\% và $1,5 \%$. Tỷ lệ nhiễm HCV ở các khu vực khác thay đổi từ $0,5-1 \%$. Xơ gan được định nghĩa là tình trạng tốn thương gan mạn tính do các tổn thương lặp đi lặp lại trong thời gian dài của nhiều căn nguyển. Đây cũng là một trong 10 nguyên nhân hàng đầu gây tử vong trên toàn thế giới - theo thống kê năm 2018 [2]. Khi xơ gan tiến triển đến giai đoạn mất bù các biến chứng xảy ra nhiều hơn và nặng hơn, thường gặp nhất là giãn tĩnh mạch thực quản (có thể gầy xuất huyết), cổ trướng, hội chứng gan thận, nhiễm trùng dịch báng... Tiên lượng bệnh nhân (BN) càng nặng nếu có càng nhiều biến chứng. Sinh thiết gan là tiêu chuẩn vàng để chẩn đoán xơ gan, tuy nhiên phương pháp này cũng có những hạn chế vì đây là một thủ thuật xâm lấn, giá thành cao, có nguy cơ biên chứng với $0,3-$ $0,6 \%$, nguy cơ tử vong $0,05 \%$ và $\mathrm{BN}$ phải được theo dôi trong bệnh viện từ 6 đến 12 tiếng sau thủ thuật [3]. Do đó, trong những năm gần đây, sự phát triển của các kỹ thuật không xâm lấn với sự đánh giá với các thuật toán đã trở nên có giá trị trong việc đánh giá xơ hóa gan. Chỉ số AST/số lượng tiểu cầu (APRI: AST platelet ratio index) để đánh giá mức độ xơ hóa gan tiên triển hoặc xơ gan [3]. Từ năm 2015, phác đồ dựa trền thuốc kháng vi rút trực tiếp (DAA: direct-acting antiviral agents) đã được sử dụng Việt Nam để điều trị cho $\mathrm{BN}$ nhiễm vi rút viêm gan $\mathrm{C}$ mạn (HCV), tỷ lệ đáp ứng vi rút bền vững (SVR) ở BN HCV đạt được trên $95 \%$ ở một số nghiên cứu trong nước [1]. Hiện nay có rất ít dữ liêu cho thây sự thoái triển của xơ hóa ở những BN đã đạt được SVR. Do đó, chúng tôi thực hiện nghiên cứu này nhằm khảo sát sự thay đổi chỉ số xơ hoá gan APRI sau đạt đáp ứng vi rút bền vững ở bênh nhân viêm gan vi rút $\mathrm{C}$ mạn được điêu trị bẳng thuốc kháng vi rút trực tiếp.

II. ĐỐI TƯỢNG VÀ PHƯƠNG PHÁP NGHIÊN CỨU Thiết kế nghiên cứu: Nghiên cứu hồi cứu tiến hành trên hồ sơ bệnh án của 240 BN viêm gan vi rút $\mathrm{C}$ mạn.

\section{Đối tượng nghiên cứu}

Tiêu chuẩn chơn bệnh nhân nghiên cứu: Hồ sơ bệnh án BN HCV, đủ 18 tuổi trở lên, được chỉ định điều trị bằng các phác đồ DAA (không có IFN và ribavirin), có đầy đủ xét nghiệm đánh giá trước, trong và sau khi kết thúc điều trị 12 tuần tại Phòng khám viêm gan - Khoa khám bệnh - bệnh viện Đại học Y Dược TP. HCM, thời gian từ tháng 01/2018 đến 12/2019.

Tiêu chuân loai trừ: Phu nữ có thai, BN không sử dụng phác đồ DAA đủ thời gian quy định, BN không được xét nghiệm số lượng tiểu cầu đầy đủ. Các bệnh viêm gan đồng mắc khác như viêm gan vi rút B mạn, viêm gan do rượu,

Cỡ mẫu: Lãyy mẫu thuân tiên. Tất cả bênh nhân thoả tiêu chuẩn chọn mẫu và không có tiêu chuẩn loại trừ?.

Cõ mẫu: Chon mẫu thuân tiên (thỏa tiêu chuẩn chọn mẫu và không có tiêu chuẩn loại trừ')

Các bước tiến hành và phân tích số liệu: Số liệu nghiên cứu được thu thập tại phòng khám Viêm gan - bệnh viện Đại học Y Dược TP. Hồ Chí Minh. Các thông tin được thu thập bao gồm: Thông tin hành chính, bệnh sử, tiền căn và khám lâm sàng từng $\mathrm{BN}$. Ghi nhận kết quả lâm sàng và cận lâm sàng trước khi điêu trị (TO), sau khi sử dụng phác đồ DAA, BN được ghi nhận kết quả tại thời điểm sau khi kết thúc điều trị 12 tuần (3 tháng) để xác định SVR, 24 tuần (6 tháng) và sau khi kết thúc điều tri 48 tuần (1 năm).

Kiểm soát sai lềnh thông tin: Đinh nghĩa rõ và cu thể các biến số trong nghiên cứu. Nghiên cứu viên hiểu rõ bản chất dữ liệu và nắm vững phương pháp thu nhập dữ liệu. Đối với mỗi loại thông số, chỉ sử dụng thống nhất 1 thiết bị cân đo. Nhập số liệu, phân tích và xử lý thống kê bằng phần mềm Minitab 18. Chẩn đoán xác định xơ gan dựa trên lâm sàng (hội chứng suy tế bào gan và hội chứng tăng áp lực tĩnh mạch cửa) và hình ảnh xơ gan trên siêu âm bụng.

Chỉ số APRI được tính theo công thức [4]:

$$
\text { APRI }=\frac{A S T(U / L) / A S T(U L T)}{\left(T i e ̂ ̉ u \text { cầu }\left(10^{9} / L\right)\right.} \times 100
$$

(ULN là giới hạn trên của giá trị bình thường của AST: upper limit of normal AST).

Một số giá trị cắt (cut-off) của số điểm APRI thường được sử dụng là: < 1: xơ hóa gan có ý nghĩa chưa xác định, ít có khả năng xơ gan; 1 2: nhiêu khả năng xơ hóa gan nhưng xớ gan chưa xác định; > 2: xơ hóa gan có ý nghĩa và nhiều khả năng xơ gan. 
Phân tích số liệu theo phần mềm SPSS 20.0. Các mối liên hệ được kiểm định bằng phép kiểm $X 2$ với $p<0,05$ được xem là có ý nghĩa thống kê.

Vấn đề đạo đức: Nghiên cứu đã được thông qua hội đồng đạo đức trong nghiên cứu $Y$ sinh học, Trường Đại học Y Dược TP. HCM.

\section{KẾT QUẢ NGHIÊN CỨU}

Đặc điểm bệnh nhân. Kết quả có 184 hồ sơ bệnh án của BÑ đủ tiêu chuẩn được đưa vào nghiên cứu với tuổi trung bình là $57,1 \pm 13,4$. Phân bố về độ tuổi, giới và cận lâm sàng được trình bày tại Bảng 1 . Trong $184 \mathrm{BN}$ có 71 $(38,6 \%)$ là nam và $113(61,4 \%)$ là nữ, tỷ lệ nam/nữ là $1 / 1,6$. Phần lớn của nhóm nghiên cứu là BN HCV chưa có xơ gan là 96/184, chiếm tỷ lệ $52,2 \%$. Chủ yếu BN HCV týp 6 chiếm tỷ lệ cao nhất trong nhóm nghiên cứu (48,4\%), tiếp theo là HCV týp 1 và týp 2 lần lượt là $36,4 \%$ và $9,8 \%$. Tải lượng vi rút viêm gan C (HCV-RNA) của mẫu nghiên cứu phân bố trong khoảng 4,25 - 6,51 $\log _{10} \mathrm{IU} / \mathrm{ml}$, với trung bình là $5,82 \log _{10} \mathrm{IU} / \mathrm{ml}$. Giá trị trung bình của $A S T, A L T$ và GGT lần lượt là $45 \mathrm{U} / \mathrm{L}, 47 \mathrm{U} / \mathrm{L}$ và $52 \mathrm{U} / \mathrm{L}$. Trong các phác đồ điều trị HCV, Sofosbuvir/Ledipasvir được lựa chọn nhiều nhất với 98 (53,3\%) BN. Các phác đồ Sofosbuvir/Velpatasvir, Sofosbuvir/Daclatasvir và Elbasvir/Grazoprevir có tỷ lệ lần lượt là $56 \mathrm{BN}$ $(30,4 \%) ; 28 \mathrm{BN}(15,2 \%)$ và $2 \mathrm{BN}(1,1 \%)$. Mặc dù đáp ứng vi rút nhanh (RVR) chiếm 159/184 $(86,4 \%)$, nhưng đáp ứng vi rút bền vững (SVR) có tỷ lệ cao với 184/184 (100\%).

Bảng 1. Đặc điểm bệnh nhân trước khi điều trị thuốc kháng vi rút trực tiếp (DAA) $(n=184)$

\begin{tabular}{|c|c|}
\hline Giá trị & Tống (n=184) \\
\hline Tuối (năm) (TB \pm ĐLC) & $57 \pm 13$ \\
\hline Giới tính [n (\%)]: Nam & $71(38,6 \%)$ \\
Nứ & $113(61,4 \%)$ \\
\hline Mức đố xơ gan [n $(\%)]$ & \\
Không xơ gan & $96(52,2 \%)$ \\
Xơ gan & $88(47,8 \%)$ \\
\hline Kiểu gen [n (\%)]: Týp 1 & $67(36,4 \%)$ \\
Týp 2 & $18(9,8 \%)$ \\
Tyýp 6 & $89(48,4 \%)$ \\
Không xác định & $10(5,4 \%)$ \\
\hline HCV RNA (log $10 \mathrm{IU} / \mathrm{ml})$ & $5,82(4,25-6,51)$ \\
\hline
\end{tabular}

\begin{tabular}{|c|c|}
\hline (Trung vị - KTPV) & \\
\hline ALT (U/L) (Trung vị-KTPV) & $47(26-68)$ \\
\hline AST (U/L) (Trung vị-KTPV) & $45(30-69)$ \\
\hline GGT (U/L) (Trung vị-KTPV) & $52(28-97)$ \\
\hline Phác đồ điêu trị [n (\%)] & \\
Sofosbuvir/Ledipasvir & $98(53,3 \%)$ \\
Sofosbuvir/Velpatasvir & $56(30,4 \%)$ \\
Sofosbuvir/Daclatasvir & $28(15,2 \%)$ \\
Elbasvir/Grazoprevir & $2(1,1 \%)$ \\
\hline Hiệu quả đîêu trị [n (\%)] & \\
Đáp ứng vi rút nhanh (RVR) & $159(86,4 \%)$ \\
Đáp ứng vi rút bền vững & $184(100 \%)$ \\
(SVR) & \\
\hline
\end{tabular}

So sánh thay đổi mức độ xơ hoá gan dựa vào APRI. $B N$ được chia thành 2 nhóm với viểm gan mạn $(96 \mathrm{BN})$ và xơ gan $(88 \mathrm{BN})$. Các giá trị APRI được ghi nhận tại thời điểm trước điêu trị, 6 tháng sau điều trị và 12 tháng sau điều trị. Giá trị APRI trước điều trị của BN viêm gan mạn và xơ gan do HCV được thể hiện tại Bảng 2. Các mức độ APRI giữa 2 nhóm có ý nghĩa thống kê với $p=0,003$. Với điểm APRI < 1 , nhóm BN viêm gan mạn chiếm tỷ lệ cao hơn nhóm xơ gan, lần lượt là $67 \%$ so với $34 \%$. Ngược lại, với điểm APRI >2, nhóm BN xơ gan có tỷ lệ cao hơn so với nhóm viêm gan mạn, với tỷ lệ là $28 \%$ so với $10 \%$.

Bảng 2. Giá trị APRI trước điều trị của bệnh nhân viêm gan vi rút $C$ mạn và xơ gan do HCV.

\begin{tabular}{|c|c|c|c|}
\hline APRI & $\begin{array}{c}\text { Viêm gan vi } \\
\text { rút C man } \\
(\mathrm{n}=96) \\
{[\mathrm{n}(\%)]}\end{array}$ & $\begin{array}{c}\text { Xơ gan do } \\
\mathbf{H C V} \\
(\mathrm{n}=88) \\
{[\mathrm{n}(\%)]}\end{array}$ & Giá trị p \\
\hline $\begin{array}{c}\text { Median } \\
\mathbf{< 1}\end{array}$ & $\begin{array}{c}(0,71 \\
(0,39-1,12)\end{array}$ & $\begin{array}{c}1,13 \\
(0,68-2,25)\end{array}$ & $\mathbf{0 , 0 0 3}$ \\
$\mathbf{1 - 2}>$ & $67(69,8)$ & $34(38,6)$ & \\
$>\mathbf{2}$ & $19(19,8)$ & $26(29,6)$ & \\
\hline
\end{tabular}

Sau khi điều trị thuốc DAA, BN được theo dõi tiếp tại thời điểm 6 tháng và 12 sau khi kết thúc điều trị nhằm khảo sát thay đổi mức độ xơ hoá gan dựa vào chỉ số APRI. Thay đổi giá trị APRI ở $\mathrm{BN}$ viểm gan mạn và xơ gan do HCV tại thời điểm trước điều trị, 6 tháng và 12 tháng sau khi kết thúc điều trị được thể hiện tại Bảng 3 và Bảng 4.

Bảng 3. Thay đổi giá trị APRI ở bênh nhân viêm gan vi rút $C$ mạn tại thời điểm trước điều trị, 6 tháng và 12 tháng sau khi kêt thúc điều trị $(n=96)$.

\begin{tabular}{|c|c|c|c|c|c|c|}
\hline \multirow{2}{*}{ APRI } & \multicolumn{2}{|c|}{ So sánh trước điêu trị và $\mathbf{6}$ tháng } & \multicolumn{3}{|c|}{ So sánh $\mathbf{6}$ tháng và 12 tháng } \\
\cline { 2 - 7 } & Trước điêuu trị & $\mathbf{6}$ tháng & Giá trị p & $\mathbf{6}$ tháng & $\mathbf{1 2}$ tháng & Giá trị p \\
\hline Median & $0,71(0,39-1,12)$ & $0,32(0,24-0,59)$ & $\mathbf{0 , 0 1 2}$ & $0,32(0,24-0,59)$ & $0,31(0,26-0,60)$ & 0,385 \\
$<\mathbf{1}$ & $67(69,8)$ & $84(87,5)$ & & $84(87,5)$ & $85(88,5)$ & \\
$\mathbf{1 - 2}$ & $19(19,8)$ & $12(12,5)$ & & $12(12,5)$ & $11(11,5)$ & \\
$>\mathbf{2}$ & $10(10,4)$ & $0(0)$ & & $0(0)$ & $0(0)$ & \\
\hline
\end{tabular}


Ở nhóm BN viêm gan man, thay đổi mức độ xơ hoá gan APRI thay đổi có ý nghĩa thống kê sau 6 tháng kết thúc điêu trị so với ban đầu với $(p=0,012)$. Tuy nhiên, khi so sánh thời gian theo dõi sau đó là 12 tháng so với 6 tháng, kết quả không có sự khác biệt có ý nghĩa thống kê với $p=0,385$.

Bảng 4. Thay đổi giá trị APRI ở bệnh nhân xơ gan vi rút C mạn tại thời điểm trước điều trị, 6 tháng và 12 tháng sau khi kêt thúc điều trị $(n=88)$.

\begin{tabular}{|c|c|c|c|c|c|c|}
\hline \multirow{2}{*}{ APRI } & \multicolumn{2}{|c|}{ So sánh trước điêuu trị và $\mathbf{6}$ tháng } & \multicolumn{3}{c|}{ So sánh $\mathbf{6}$ tháng và 12 tháng } \\
\cline { 2 - 6 } & Trước điều trị & $\mathbf{6}$ tháng & Giá trị p & $\mathbf{6}$ tháng & $\mathbf{1 2}$ tháng & Giá trị p \\
\hline Median & $1,13(0,68-2,25)$ & $0,41(0,28-0,67)$ & $<\mathbf{0 , 0 0 1}$ & $0,41(0,28-0,67)$ & $0,40(0,28-0,66)$ & 0,762 \\
$\mathbf{< 1}$ & $34(38,6)$ & $79(89,8)$ & & $79(89,8)$ & $78(88,6)$ & \\
$\mathbf{1 - 2}$ & $26(29,6)$ & $9(10,2)$ & & $9(10,2)$ & $10(11,4)$ & \\
$\mathbf{>} 2$ & $28(31,8)$ & $0(0)$ & & $0(0)$ & $0(0)$ & \\
\hline
\end{tabular}

Ơ nhóm BN xơ gan, mức độ xơ hoá gan APRI giảm có ý nghĩa thống kê ở tất cả các giá trị ở thời điểm 6 tháng sau khi kết thúc điêu trị so với giá trị ban đầu trước điêuu trị với $p<0,001$. Tại thời điểm 12 tháng sau kết thúc điều trị, khác biệt không có ý nghĩa thống kê so với thời điểm 6 thảng ( $p$ $=0,762$ ).

\section{BÀN LUẬN}

Có 184 BN được được đưa vào nghiên cứu với $96 \mathrm{BN}$ viêm gan mạn và $88 \mathrm{BN}$ xơ gan do HCV. BN viêm gan mạn hoặc xơ gan do HCV đã điều trị DAA vẫn cần được theo dõi trong những năm tiếp theo vì xơ gan mất bù và ung thư biểu mô tế bào gan vẫn có thể xuất hiện mặc dù đã đạt SVR [2]. Trong các công cụ đánh giá mức độ xớ hoá gan, sinh thiết gan thường được thay thế bằng các phương pháp không xâm lấn khác. Nhiều nghiên cứu đã chứng minh APRI là công cụ dễ dàng, hữu ích và ít tốn kém trong việc dự đoán xơ gan cũng như thay đổi mức độ xớ hoá gan ở BN viêm gan mạn [5]. Trong nghiên cứu của chúng tôi, các chỉ số men gan ALT, AST và GGT đều cao hơn giá trị trên bình thường. Các chỉ số trên phản ánh tình trạng tổn thương tế bào gan. Các giá trị này cũng phản ánh nhiều nghiên cứu cho rằng $\mathrm{BN}$ HCV sẽ diễn tiến thành xơ gan và/hoăcc ung thư gan nếu như không được điều trị. Do đó, BN HCV dù đạt được SVR khi điều $D A A$, nên được theo dõi thường xuyên sau đó để phát hiện quá trình xơ hoá gan nhằm điêu trị và phòng ngừa các biến chứng có thể xãy ra. Nghiên cứu của Bachofner JA và cộng sự năm 2017 cho thấy giảm có ý nghĩa các chỉ số đánh giá mức độ xơ hoá gan như APRI, FIB-4 và đo độ đàn hồi gan (TE) ở những $B N$ được điều trị DAA đạt được SVR [5].

Nghiên cứu của chúng tôi đánh giá sự thay đổi mức độ xơ hoá gan APRI ở nhóm BN viêm gan mạn tại 2 thời điểm, trước điêu trị và sau khi kết thúc điều trị 6 tháng. Sự thay đổi về mức độ xơ hoá rất có giá trị $(\mathrm{p}=0,012)$. Kết quả này cho thây hiệu quả của DAA trong điêu trị HCV khi đạt SVR sẽ cải thiện số lượng tiểu cầu, mực độ xớ hoá gan... Tuy nhiên chúng tôi không tìm thây sự khác biệt có ý nghĩa ở thời gian sau đó ở hai thời điểm, 6 tháng sau và 12 tháng sau điều trị $(p=0,385)$. Kết quả này tương đồng với nghiên của Anca $L$ và cộng sự [6] cho thấy cải thiện mức độ xơ hoá khi BN đạt SVR sau khi điều trị DAA.

Theo hướng dẫn điều trị của Hội gan mật Hoa Kỳ (AASLD) [2] và Hội gan mật Châu Ẩu (EASL) [7], BN xơ gan do HCV được khuyến cáo điêuu trị DAA nhằm làm giảm diễn tiến xơ gan của bệnh. Nghiên cứu của Tamaki và cộng sự [8] cho thây APRI có thể theo dõi tiến triễn xớ hoá gán mà không cần thực hiện sinh thiết gan ở $\mathrm{BN}$ xơ gan còn bù. Trong nghiên cứu của chúng tôi, sự khác biệt trong cải thiện mức độ xơ hoá gan sau khi điều DAA ở BN xớ gan có ý nghĩa thống kê với $p<0,001$ (thời điểm 6 tháng sau khi kết thúc điêuu trị so với giá trị ban đâu). Giá trị này giảm có thể do cải thiện tổn thương tế bào gan sau khi điêu trị DAA và các men gan transaminase giảm. Tuy nhiên, khi theo dõi tiếp ở những BN xơ gan, sự khác biệt không có ý nghĩa thống kê ở thời điểm 12 tháng sau điều trị so với thời điểm 6 tháng $(p=0,762)$. Điều này cho thấy có sự cải thiện tình trạng xơ hoá ở những $B N$ xơ gan, từ đó giảm tỷ lệ tử vong do các biến chứng của xơ gan.

\section{KẾT LUÂ̂N}

Chỉ số đánh giá mức độ xơ hoá gan APRI thay đổi có ý nghĩa thống kê ở BN viêm gan hoặc xớ gan do HCV ở thời điểm sau 6 tháng khi kêt thúc điều trị DAA. Do đó, BN viêm gan mạn hoặc xơ gan do HCV nên được điều trị DAA sớm để hạn chế diễn tiến của bệnh gan mạn tính.

\section{TÀI LIẸU THAM KHẢO}

1. Bộ Y Tế, Hướng dẫn chẩn đoán và điều trị viêm gan vi rút $C$ (Ban hành kèm theo Quyết định số 5012/QĐ-BYT ngày 20/09/2016 của Bộ trưởng Bộ Y tế). 2016. 
2. Ghany MG, Marks KM, Morgan TR et al. Hepatitis C Guidance 2019 Update: AASLD-IDSA Recommendations for Testing, Managing, and Treating Hepatitis C Virus Infection. Hepatology. 2019.

3. Hà Vũ, Bùi Hữu Hoàng. Giá trị của chỉ số APRI và FIB-4 trong tiên đoán giãn tĩnh mạch thực quản ở bệnh nhân xơ gan. Tạp chí Y Học Thành phố Hồ Chí Minh. 2015; 19(1):97-102. 3

4. Chou $\mathbf{R}$, Wasson $\mathbf{N}$. Blood tests to diagnose fibrosis or cirrhosis in patients with chronic hepatitis C virus infection: A systematic review. Annals of Internal Medicine. 2013; 158:807-820.

5. Bachofner JA, Valli PV, Kröger A et al. Direct antiviral agent treatment of chronic hepatitis C results in rapid regression of transient elastography and fibrosis markers fibrosis-4 score and aspartate aminotransferase-platelet ratio index. Liver International. 2017; 37:369-376.

6. Anca $L$, Cristina $P$, Luciana $\mathbf{N}$ et al. Dynamics of APRI and FIB-4 in HCV cirrhotic patients who achieved SVR after DAA therapy. Experimental and Therapeutic Medicine. 2021; 21(1):99.

7. European Association for the Study of the Liver. EASL recommendations on treatment of hepatitis C: Final update of the series. Journal of Hepatology. 2020; 73 (5): $1170-1218$.

8. Tamaki N, Kurosaki $M$, Tanaka $K$ et al. Noninvasive estimation of fibrosis progression overtime using the FIB-4 index in chronic hepatitis C. Journal of Viral Hepatitis. 2013; 20:72-76.

\section{NGHIÊN CỨU ĐĂC ĐIỂM CÁC TRƯỜNG HỢP U VÚ ĐƯợC PHẪU THUÂ̂T TẠI BÊ̂NH VIỆN TỪ DŨ}

\section{TÓM TẮT}

Đặt vấn đề: Ung thư vú là loại ung thư thường gặp nhất ở phụ nữ và đứng thứ hai trong số các nguyên nhân gâyy tử vong do ung thư ở phụ nữ. Các tốn thương u vú xuất hiện trên lâm sàng dưới dạng những u cục dạng bướu, có khi giống bướu lành, có khi giống ung thư, và dế gây chẩn đoán lầm với ung thư làm kết quả sau khi phân tích giải phẫu bệnh lý không như chẩn đoán trước phẫu thuật. Mục tiêu: Xác định tỷ lệ các hình thái giải phẫu bệnh lý của u vú được phẫu thuật tại bênh viện Từ Dũ và phân tích giá trị của siêu âm, nhũ ảnh, chọc hút tế bào bằng kim nhỏ. Phương pháp: Nghiên cứu mô tả dọc hồi cứu trên 475 trướng hợp phẩu thuật u vú từ 01/2016 đến 12/2020 tai bênh viên Từ Dũ. Kết quả: Ung thư vú chiếm 8,6\% (KTC 95\%: 6,1-11,2), u vú lành tính chiếm $91,4 \%$ (KTC 95\%: 88,8-93,9). U sợi tuyến lành của vú chiếm 72,6\% (KTC 95\%: 65,5-73,8) là dang hình thái u lành tính phổ biến nhất. Carcinom ống tuyến vú chiếm 78,0\% (KTC 95\%: 63,4-90,2) là dạng hình thái ung thư vú phổ biến nhất. Độ nhạy, độ đăc hiệu, giá trị tiên đoán dương, giá trị tiên đoán âm của siểu âm $(0,537 ; 0,855 ; 0,259 ; 0,951)$, nhũ ảnh $(0,853$; $0,335 ; 0,201 ; 0,921)$, FNA $(0,486 ; 0,987 ; 0,818 ; 0,941)$. Kết luận: Nhũ ảnh có vai trò sàng lọc tốt nhất. Siêu âm và FNA có vai trò sàng loc thấp.

Tư khóa: Hình thái u vú, siêu âm vú, nhũ ảnh, chọc hút tế bào kim nhỏ (FNA)

${ }^{1}$ Bệnh viện Triều $A n$

${ }^{2}$ Đại học Y Dước TP. Hồ Chí Minh

${ }^{3}$ Bệnh viện Từ Dũ

Chiu trách nhiệm chính: Võ Minh Tuấn

Email: vominhtuan@ump.edu.vn

Ngày nhận bài: 5.4.2021

Ngày phản biên khoa hoc: 18.5 .2021

Ngày duyệt bài: 26.5.2021
Tống Thị Mỹ Phụng1, Võ Minh Tuấn², Võ Thanh Nhân ${ }^{3}$, Phạm Thị Mộng Tho

\section{SUMMARY}

RESEARCH CHARACTERISTICS OF SURGICAL BREAST TUMOR CASES AT TU DU HOSPITAL

Background: Breast cancer is the most common cancer in women and the second leading cause of cancer death in women. Breast tumor lesions appear clinically in the form of tumour-like lumps, sometimes resembling benign tumors, sometimes cancerous, and easily misdiagnosed with cancer as a result of pathological analysis unlike preoperative diagnosis. Objective: Determining the rate of pathological anatomical forms of breast tumors operated at Tu Du hospital and analyzing the value of ultrasound, mammography, fine needle aspiration. Methods: Retrospective longitudinal descriptive study on 475 breast tumor surgery cases from January 2016 to December 2020 at Tu Du hospital. Results: Breast cancer accounting for $8.6 \%$ (95\% CI: 6.1-11.2), benign breast tumors accounting for $91.4 \%$ (95\% CI: $88,8-93.9)$. The benign fibroadenoma of the breast accounts for $72.6 \%$ (95\% CI: $65.5-73.8$ ) which is the most popular form of benign tumor morphological. Breast ductal carcinoma accounts for $78.0 \%$ (95\% CI: $63.4-90.2$ ) is the most popular form of breast cancer. Sensitivity, specificity, positive predictive value, negative predictive value of ultrasound $(0.537 ; 0.855$; $0.259 ; 0.951)$, mammography $(0.853 ; 0.335 ; 0.201$; $0.921)$ FNA (0.486; $0.987 ; 0.818 ; 0.941)$. Conclusions: Mammography has the best screening role. Ultrasound and FNA have a low screening role.

Keywords: Breast tumor morphology, breast ultrasound, mammography, fine needle aspiration (FNA)

\section{I. ĐĂT VẤN ĐỀ}

Tuyến vú của phụ nữ là nơi chịu nhiều ảnh hưởng của kích thích tố nữ. Những rối loạn kích 